\title{
Obstructive sleep apnea in the adult obese patient: implications for airway management
}

\author{
Jonathan L. Benumof, MD
}

UCSD Medical Center, Department of Anesthesiology, 402 Dickinson Street (8812), San Diego, CA 92103-8812, USA

Obstructive sleep apnea in the adult obese patient may be due, in part, to an increased amount of pharyngeal tissue; therefore, there is an increased risk of intubation and extubation difficulties, and pain management can be expected to be complicated by narcotic/sedative-induced pharyngeal collapse.

The number of adult obese patients with obstructive sleep apnea (OSA) is very large. It has been estimated, that among the middle-aged, $4 \%$ of men and $2 \%$ of women have clinically significant symptomatic OSA [1,2]. Prevalence rates of OSA and snoring increase with age $[3,4]$ and the data in Table 1 is considered to be representative of this relationship [5]. As another very important independent factor, $60 \%$ to $90 \%$ of persons with OSA are obese (defined as a body mass index $[\mathrm{BMI}]>29 \mathrm{~kg} / \mathrm{m}^{2}$ ) [5,6] with all indices of obesity, including BMI, waist, hip and neck circumferences, and skin fold thickness strongly and directly related to the severity of OSA [1,2,7]. Indeed, in 1993 the National Commission on Sleep Disorders Research estimated that 18 million Americans have OSA [8].

At present, $80 \%$ to $90 \%$ [9] to $95 \%$ [8] of persons with OSA are undiagnosed; obviously, this includes those who require anesthesia and surgery now. At the same time, general physician recognition of the problem is rapidly growing [10] resulting in an increase in polysomography testing of approximately $124 \%$ every three years [11]. Thus, the incidence of adult obese patients presenting for anesthesia and surgery with either a presumptive clinical and/or a sleep study diagnosis of OSA can be expected to increase five- to ten-fold in the next decade. Finally, on the basis of the facts that the mean age and weight of the USA population is increasing steadily [7], and that most excess body fat accrues after 20 years of age [7], we can expect the incidence of adult obese patients with OSA presenting for anesthesia and surgery, both with and without a diagnosis of OSA, to increase for many years. 
Table 1

Distribution by age of categorical levels of AHI* (AHI = Apneas + Hyponeas/Hour of sleep)

\begin{tabular}{lllcc}
\hline Age $(\mathrm{y})$ & Habitual snoring $(\%)$ & AHI $>5(\%)$ & AHI $>10(\%)$ & AHI $>15(\%)$ \\
\hline$<25$ & 14 & 10 & 2 & 0 \\
$26-50$ & 41 & 26 & 15 & 0 \\
$>50$ & 46 & 61 & 50 & 36 \\
\hline
\end{tabular}

$\mathrm{AHI}=$ Apnea Hyponea Index.

* From Strohl KP, Redline S. Recognition of sleep apnea. Am J Respir Crit Care Med 1996;154: $279-86$.

This review is limited to considering OSA in adult obese patients for two reasons. First, although other causes of OSA may coexist, an important mechanism of the obstruction in obese patients, namely, pharyngeal airway tissue enlargement, is relatively specific to the obese patient. To the contrary, the etiology of OSA in nonobese patients appears to be different and consists of predominantly of craniofacial and orofacial bony abnormalities [12]. However, excess neck fat may be present in nonobese snorers [13] and superimposition of obesity on any pre-existing bony abnormality may increase the severity of OSA. Similarly, nasal pathology and tonsillar hypertrophy are well-defined obvious causes of obstructed breathing in patients of any weight and are not considered here. Because OSA in pediatric patients is usually related to bony, nasal, and tonsillar pathology [14], pediatric patients are also not considered in this review. Second, obesity is by far the single most important physical characteristic associated with OSA in the adult population (60\%-90\% incidence) $[5,6]$ and therefore the large majority of the adult OSA population is covered by this review.

\section{Definition of OSA terms}

OSA is defined as cessation of airflow for more than 10 seconds despite continuing ventilatory effort, five or more times per hour of sleep, and is usually associated with a decrease in arterial oxygen saturation $\left(\mathrm{SaO}_{2}\right)$ of more than $4 \%$ (Table 2) [15]. Obstructive sleep hypopnea (OSH) is defined as a decrease in airflow of more than $50 \%$ for more than 10 seconds, 15 or more times per hour of sleep, and is usually associated with snoring and may be associated with a decrease in $\mathrm{SaO} 2$ of greater than 4\% (Table 2). Both OSA and OSH repeatedly disrupt sleep due to increased ventilatory effort-induced arousal which, in turn, causes daytime sleepiness and altered cardiopulmonary function (Table 2) [15].

Table 2

Major characteristics of obstructive sleep apnea (OSA) and obstructive sleep hypopnea (OSH)*

\begin{tabular}{llllll}
\hline Obstruction & $\downarrow$ in Airflow $>10 \mathrm{~s}$ & Times $/ \mathrm{h}$ & $\downarrow$ in $\mathrm{O}_{2}$ saturation & Disrupted sleep & Daytime sleepiness \\
\hline OSA & $100 \%$ & $>5$ & $\geq 4 \%$ & Yes & Yes \\
OSH & $>50 \%$ & $>15$ & $\geq 4 \%$ & Yes & Yes \\
\hline
\end{tabular}

* Data from Strollo PJ, Rogers RM. Obstructive sleep apnea. Current concepts. N Engl J Med 1996;334:99-104. 


\section{Pathophysiology of OSA in the adult obese patient}

\section{Normal pharyngeal muscle activity}

The contraction of the diaphragm against the high resistance offered by the nose during inspiration creates a subatmospheric intra-airway pressure, which may narrow the collapsible segments in the pharynx. There are three collapsible pharyngeal segments: the retropalatal pharynx (velo- or nasopharynx, posterior to the soft palate), the retroglossal pharynx (oropharynx, posterior to the tongue from the tip of the uvula to the tip of the epiglottis), and the retroepiglottic pharynx (laryngo- or hypopharynx, posterior to the epiglottis) (Fig. 1). These pharyngeal segments are collapsible because the anterior and lateral walls lack bony support. The adult human is the only mammal to have an oropharynx (in all other mammals the tip of the uvula touches the tip of the epiglottis) and to suffer from OSA [16].

Patency of the collapsible segments of the pharynx depends on the inspiratory function of the pharyngeal dilator muscles which act to stiffen or distend the collapsible pharyngeal airway during inspiration [17]. The larger the negative inspiratory pressure, the larger the force of contraction of the pharyngeal dilator muscles required to keep the airway open. This negative pressure reflex response seems to be driven by pressure-sensitive airway receptors since pharyngeal anesthesia diminishes or abolishes it $[18,19]$. Activity of these muscles, at least during wakefulness, is thus precisely controlled both to maintain upper airway patency and to allow hyperventilation during hypoxia or hypercapnia. The inspiratory patency of the retropalatal, retroglossal, and retroepiglottic pharynx is caused by contraction of the tensor palatini, the genioglossus, and the hyoid bone muscles, respectively (Fig. 1) [18,20].

The tensor palatini retracts the soft palate away from the posterior pharyngeal wall, thereby maintaining retropalatal pharyngeal patency during nasal breathing. The action of the tensor palatini is predominantly tonic [20]. Tonic activity of the tensor palatini decreases during sleep and correlates well with increased upper airway resistance (UAR) during sleep [17,20].

The genioglossus moves the tongue anteriorly to open the retroglossal air space and is considered to be the most important muscle in keeping the upper airway patent. The point of insertion of the genioglossus on the mandible determines the efficiency of genioglossus muscle contraction; anterior insertion is advantageous. The action of the genioglossus is phasic with inspiration [17]; this activity decreases with sleep in normal subjects and almost ceases during deep rapid eye movement (REM) sleep and is abolished in patients with OSA at the onset of an apnea and increases at the termination of an obstruction [17].

The muscles that cause forward movement of the hyoid bone (geniohyoid, sternohyoid, thyrohyoid) are thought to enlarge and stabilize the retroepiglottic laryngopharynx by tensing the hyoepiglottic ligament. The activity of these muscles are phasic with inspiration and the activity of these muscles correlates inversely with UAR $[17,20]$. Factors that influence hyoid position, such as neck 


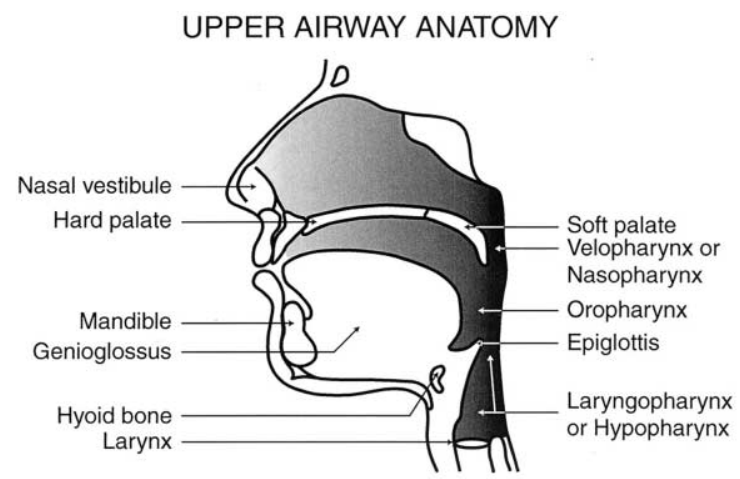

\section{ACTION OF THE UPPER AIRWAY DILATOR MUSCLES}

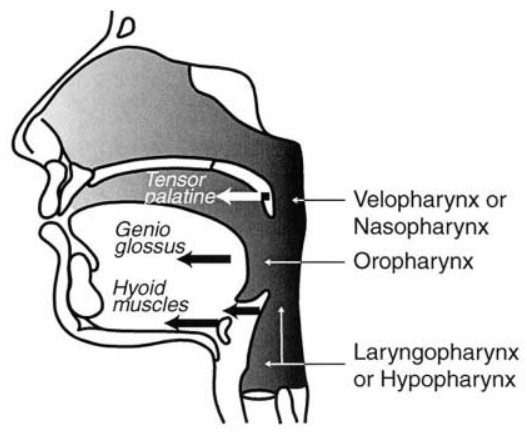

SITES OF OBSTRUCTION DURING SLEEP APNEA

airspace

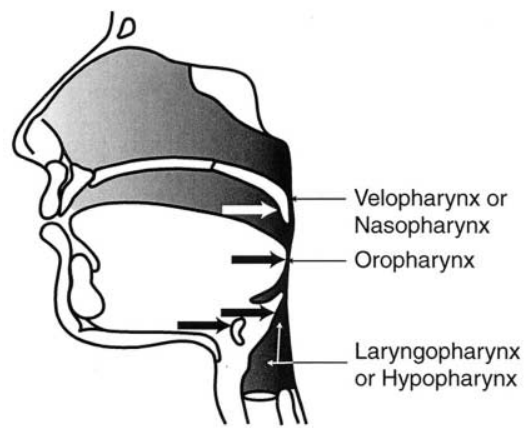

Fig. 1. The upper panel schematic shows the important upper airway anatomy. The nasopharynx ends at the tip of the uvula; the oropharynx extends from the tip of the uvula to the epiglottis; the laryngopharynx extends from the tip of the epiglottis to the posterior cricoid cartilage. The middle panel shows the action of the most important dilator muscles of the upper airway. The tensor palatine, genioglossus, and hyoid muscles enlarge the nasopharynx, oropharynx, and the laryngopharynx, respectively. The bottom panel shows collapse of the nasopharynx at the palatal level, the oropharynx at the glottic level, and the laryngopharynx at the epiglottic level. (From Benumof JL. Obstructive sleep apnea in the adult obese patient: implications for airway management. J Clin Anesth 2001;13(2):144-56, with permission.) 
flexion or mandibular abnormalities, can adversely affect the function of these muscles, leading to narrowing of the laryngopharynx.

\section{Normal sleep}

The relation between the anatomy and muscle function in the upper airway becomes critical during sleep. In adults, a typical night of sleep consists of four to six cycles of non-rapid eye movement (NREM) sleep followed by REM sleep. There are four stages of NREM sleep which represent progressively deeper sleep with progressive slowing of the electroencephalogram (EEG) waves. Stages 3 and 4 of NREM sleep differ only in the relative amount of slow waves and together Stage 3 and 4 are called slow wave or deep sleep and is a restorative period of sleep. REM sleep is also very deep sleep and is almost the exclusive domain of dreaming [18]. REM sleep is characterized by a generalized loss of muscle tone as evidenced by electromyography (EMG). However, the eye muscles are not paralyzed, intermittent conjugate REMs still occur, and can be monitored by electro-oculography (EOG).

During NREM sleep, the rhythmic activity of the upper airway muscles decreases, UAR increases significantly and can be twice that during the awake state [21,22]. In REM sleep, the activity of the upper airway muscles can disappear completely and UAR increases even further. As UAR increases, the pharyngeal subatmospheric pressure generated by a given diaphragmatic contraction increases [23]. As pharyngeal pressure becomes more negative, pharyngeal collapse increases. Magnetic resonance imaging, with and without nasal continuous positive airway pressure (N-CPAP) (used as an experimental mechanism to identify movement of various parts of the pharyngeal perimeter), shows that the most important site of collapse is the compliant lateral pharyngeal walls [24].

Fig. 2 shows this sequence of events over the course of four breaths in a sleeping 39-year-old male with a BMI of $30.5 \mathrm{~kg} / \mathrm{m}^{2}$ [23]. Over these four breaths the esophageal pressure became increasingly negative, airflow progressively decreased to zero, and the fiberoptic images show near total occlusion on the third breath and total occlusion on the fourth. If the occlusion is partial, snoring is likely to occur and is due to a fluttering of the pharyngeal walls and soft palate. The sound intensity of the snoring correlates well with the severity of OSH and OSA [26]. If airway occlusion is total, then apnea results and snoring is absent.

\section{Obesity and OSA: pharyngeal pathology and incidence}

There are two reasons why obesity per se may cause OSA and OSH. First, there is an inverse relationship between obesity and pharyngeal area [27,28]. Magnetic resonance imaging shows that the decreased pharyngeal area in obesity results from deposition of adipose tissue into pharyngeal tissues. The pharyngeal structures that may increase in size with deposition of adipose tissue, from the nasopharynx down to the laryngopharynx, are the uvula, the tonsils, the tonsillar pillars, the tongue, aryepiglottic folds, and the lateral pharyngeal 

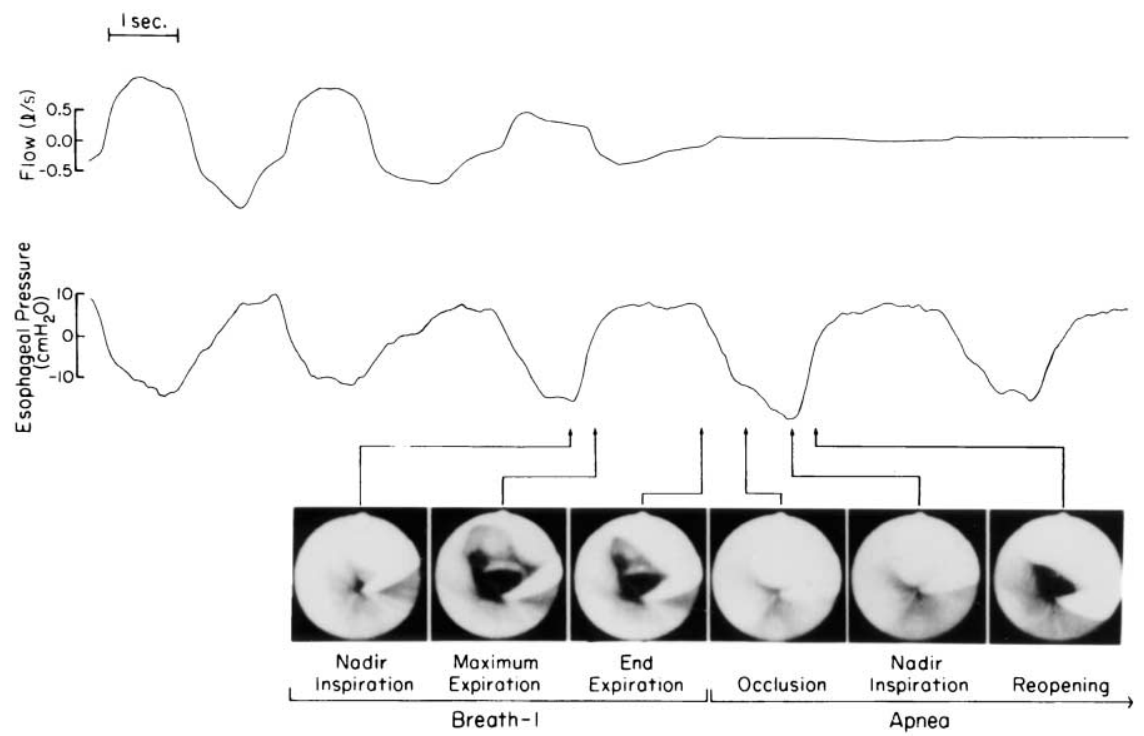

Fig. 2. An original recording (Patient $6, \mathrm{BMI}=30.5 \mathrm{~kg} / \mathrm{m}^{2}$ of Reference [23]) of airflow (flow; inspiration positive) and esophageal pressure. Tracings show three breaths leading to an obstructive apnea. Fiberoptic images are shown for the breath immediately preceding the apnea (Breath-1) and the apneic period. During Breath-1, the images selected correspond to the smallest cross-sectional area that occurred during inspiration (Nadir Inspiration), the largest cross-sectional area during expiration (Maximum Expiraton), and the cross-sectional area at the end-expiration (End Expiration). During the apnea, the images correspond to the time at which airway occlusion occurred (Occlusion), the time at which the maximum esophageal pressure was generated (Nadir Inspiration), and the time at which the airway reopened (Reopening). Within each image the dark area is the airway lumen, the lighter horseshoe shape in the middle of the image is the epiglottis, and the narrow white triangular/cylindrical shape on the right is the esophageal pressure catheter. (From Morrell MJ, Arabi Y, Zahn B, Badr MS. Progressive retropalatal narrowing preceding obstructive apnea. AM J Respir Crit Care Med 1998;158:1974-81, with permission.)

walls. Increased fat deposition in the pharynx resulting in decreased patency of the pharynx increases the likelihood that relaxation of the upper airway muscles will cause collapse of the soft-walled pharynx between the uvula and epiglottis $[4,15,16]$.

The deposition of fat in the pharynx of OSA patients appears to be predominantly into the lateral walls of the pharynx $[13,29-33]$ and the volume of fat in the lateral pharyngeal walls correlates well with the severity of OSA $[31,32]$. The converse is also true; ie, weight loss improves the pharyngeal and glottic function of OSA patients [34]. The deposition of fat into the lateral walls of the pharynx not only narrows the airway but also changes the shape of the pharynx in obese patients from being an ellipse with a long transverse (lateral) and a short anteriorposterior axis to an ellipse with a short transverse and a long anterior-posterior axis $[20,30]$. The external expression of very large internal lateral parapharyngeal fat pads is submandibular (lateral) jowls. 
It has been theorized that the change in long axis from transverse to anteriorposterior is functionally significant [35]. Since the muscles that increase upper airway size are all located along the anterior border of the pharynx (tensor palatini, genioglossus, hyoid muscles), they pull the anterior wall of the pharynx forward increasing the anterior-posterior axis (Fig. 1). Fig. 3 shows that this action of the anterior pharyngeal dilator airway muscles is less efficient in a pharynx with a long anterior-posterior elliptical axis than in one with a long transverse elliptical axis [35].

Second, the patency of the pharynx (which is a collapsible tube) is determined by the transmural pressure across its wall (the difference between the extraluminal and intraluminal pressure) and the compliance of the wall. If the compliance of the wall and intraluminal pressure (inspiratory airway pressure) are constant, then the remaining important determinant of upper airway patency is extraluminal pressure. In obese patients, extraluminal pressure is increased by superficially located fat masses [36,37]; ie, the upper airway is compressed externally. This external mechanism of increasing UAR is easily demonstrated in animals by experimentally increasing the amount of anterior cervical neck fat [36]. Therefore, it is not surprising that the neck is significantly fatter in obese OSA patients compared to equally obese non-OSA patients [38] and that the incidence and severity of OSA correlates better with increased neck circumference than with general obesity [39-41].

Snoring occurs in $30 \%$ to $40 \%$ and $15 \%$ to $25 \%$ of obese (upper 25 th percentile of the BMI) and nonobese men, respectively, and in $15 \%$ to $25 \%$ and $5 \%$ to $10 \%$ of obese and nonobese women, respectively [25]. Approximately half of individuals that snore have some degree of OSA and virtually all patients with OSH and OSA snore to some extent $[4,15]$. In two small series of persons with BMI $>45.3$ and $>50.2(\mathrm{~N}=250$ and 27$) 40 \%$ to $77 \%$ of men, but only $3 \%$ to $7 \%$ of women, had significant OSA $[42,43]$.

A

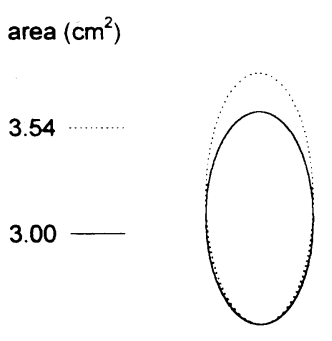

B

anterior

$\operatorname{area}\left(\mathrm{cm}^{2}\right)$

4.09

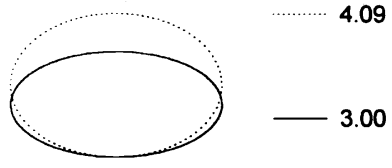

posterior

Fig. 3. The effect of a 5-mm change in the anteroposterior (AP) diameter of the airway on airway crosssectional area is shown for two equally elliptical airways with different lateral/AP ratios. (A) The lateral/ $\mathrm{AP}$ ratio $=0.5$. $(\mathrm{B})$ The lateral $/ \mathrm{AP}$ ratio $=2$. The lateral dimension of each ellipse was held constant. The solid line represents the starting area $\left(3 \mathrm{~cm}^{2}\right.$ in both ellipses), and the dotted line represents the area after a 5-mm increase in the AP diameter. The area change is greater in the ellipse with a more lateral orientation (B). (From Leiter JC. Upper airway shape. Is it important in the pathogenesis of obstructive sleep apnea? Am J Respir Crit Care Med 1996;153:894-8, with permission). 


\section{Arousal}

Over the course of an apnea a number of important respiratory events occur. First, arterial oxygen tension $\left(\mathrm{PaO}_{2}\right)$ decreases as a function of the initial $\mathrm{PaO}_{2}$, functional residual capacity (FRC), and the duration of apnea. Arousal may occur, in part, because decreased $\mathrm{PaO}_{2}$ augments carotid body output $[44,45]$. Second, arterial carbon dioxide tension $\left(\mathrm{PaCO}_{2}\right)$ increases as a function of duration of apnea. Arousal may, in part, be caused by central nervous system receptors sensitive to increasing $\mathrm{PaCO}_{2}$ [46]. Third, ventilatory effort progressively increases as the apnea proceeds as a function of both the decreasing $\mathrm{PaO}_{2}$ and increasing $\mathrm{PaCO}_{2}[47,48]$. Finally, as a function of the increased ventilatory effort, intra-airway pressure becomes progressively more negative. Arousal may, in part, be mediated by pressure-sensitive receptors in the upper airway [49].

Any or all of these four mechanisms could increase neural traffic in the reticular activating system and arouse the individual. Arousal often consists of just increased neural activity in the brain but sometimes has a visible external expression that ranges from simple one extremity twitching and movement to multiple extremity flailing and gasping for air. Once arousal occurs, the muscles of the upper airway reactivate, thereby opening the pharyngeal airway. The opening of the pharyngeal airway may cause a snorting noise. Ventilation then resumes and the hypoxia and hypercapnia are corrected [18]. The individual then returns to sleep and the cycle begins again [18].

Obviously, the arousal response is necessary for survival. However, the physiological events (see below) that surround the arousal response, if repeated often enough, will ultimately result in serious systemic pathophysiologic consequence.

\section{Systemic pathophysiology of OSA}

Fig. 4 outlines the systemic effects of the sleep $\rightarrow$ arousal $\rightarrow$ sleep cycles that occur many times during every sleep. Decreases in $\mathrm{PaO}_{2}$ during apnea may cause bradycardia with return to baseline during and after arousal. In approximately half of patients with apneic events, long sinus pauses, second-degree heart block, and ventricular dysrhythmias occur [50]. When $\mathrm{SaO}_{2}$ decreases below $60 \%$, the severity of the bradycardia and the onset of ventricular ectopy increases markedly [51]. The high incidence of arrthymias in OSA patients may explain the higher incidence of nocturnal angina and myocardial infarction in these patients [5]. Proper treatment of OSA decreases the incidence of these arrthymias [52] and presumably decreases the incidence of myocardial ischemia.

Three mechanisms may account for pulmonary hypertension (ppa) in OSA. First, decreases in $\mathrm{PaO}_{2}$ may directly cause hypoxic pulmonary vasoconstriction. Second, transmural ppa increases during each obstructive apnea because intrathoracic pressure becomes more negative with increasing ventilatory effort against the obstruction [53]. Third, increase in both pulmonary and systemic arterial pressures (Ppa and Psa) correlate directly with decreases in $\mathrm{PaO}_{2}$, with the maximal increase in both pressures occurring during the nadir in $\mathrm{PaO}_{2}$ during REM sleep [54]. Diurnal Ppa and Psa hypertension in OSA patients is likely 


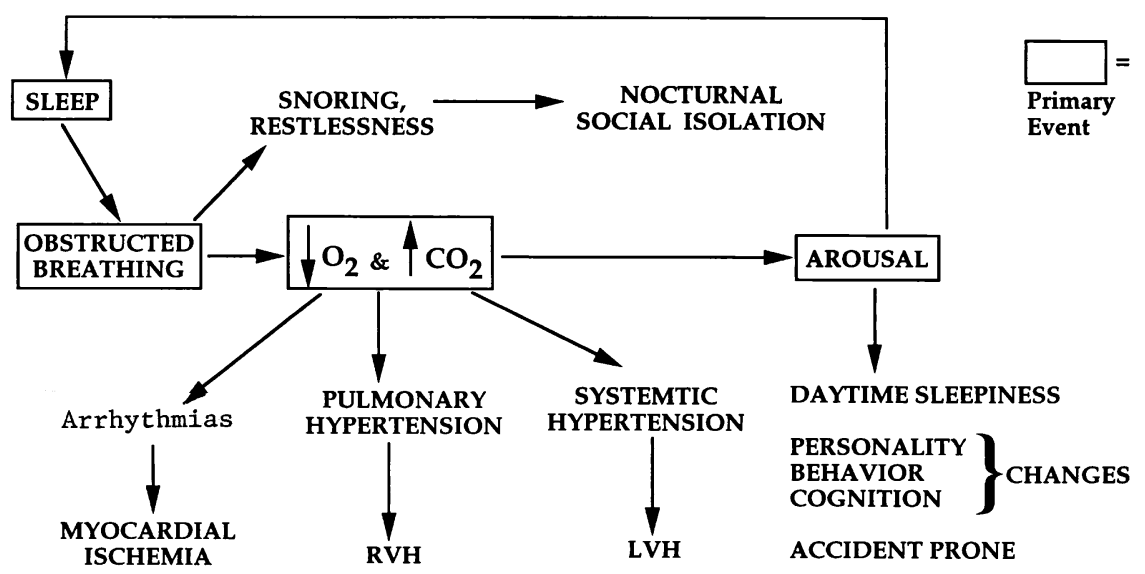

Fig. 4. The systemic pathophysiology of repeated sleep arousal sleep cycles in obstructive sleep apnea. $\mathrm{RVH}=$ ventricular hypertrophy; LVH = left ventricular hypertrophy. (From Benumof JL. Obstructive sleep apnea in the adult obese patient: implications for airway management. J Clin Anesth 2001;13(2):144-56, with permission.)

caused by the innumerable repetitive increases in sympathetic tone that occurs with each hypoxemic-hypercapnic arousal event $[15,55]$. Diurnal Psa hypertension is present in 50\% of OSA patients [56] and is independent of obesity, age. and sex $[4,6,15,52]$; proper treatment of OSA results in a decrease in psa hypertension [52].

Diurnal and nocturnal Ppa and Psa hypertension likely accounts for the $71 \%$ and $31 \%$ incidence of right and left ventricular hypertrophy, respectively, in OSA patients $[15,52,57]$. In view of the dual circulation hypertension, biventricular hypertrophy, increased incidence of arrthymias, myocardial infarction and stroke, it is not surprising that the cumulative eight-year mortality in patients with moderate untreated OSA is $37 \%$ compared to $4 \%$ in patients with mild OSA $[15,58-60]$.

The many brief periods of sleep fragmented by arousal diminishes restorative deep sleep. The sleep deprivation causes daytime sleepiness and fatigue, morning headaches, diaphoresis, nocturnal enuresis, decreased cognition and intellectual function, and personality and behavioral changes [15]. The excessive daytime sleepiness increases the risk of motor vehicle accidents for patients with OSA; the risk is reported to be six to seven times that of the general driving population $[61,62]$ and independent of any other possible confounding factor $[61,63]$.

\section{Diagnosis of OSA}

A presumptive clinical diagnosis of OSA can be made in a patient with the classical signs and symptoms of obesity, snoring and/or apnea during sleep, periodic snorting and apparent arousal, and daytime sleepiness or fatigue. 
Increased neck circumference is associated with OSA [39-41]; specifically, neck circumference of OSA patients $=41.1 \pm 3.5 \mathrm{~cm}$ versus neck circumference in patients without OSA $=38.0 \pm 3.5 \mathrm{~cm}, P<0.001$ [64].

Obesity is best expressed quantitatively as BMI:

$$
\mathrm{BMI}=\text { mass } / \text { height }^{2}=\mathrm{kg} / \mathrm{m}^{2} \text { or } 703 \times \mathrm{lb} / \mathrm{in}^{2}
$$

where underweight, normal, overweight, obesity, and morbid obesity equals $<19.0,19.0-24.9,25.0-29.9,30.0-34.9$, and $>35$, respectively [65]. Ninety percent of OSA patients may have a BMI $>28 \mathrm{~kg} / \mathrm{m}^{2}$ [5]. Whereas the principal limitation of use of the BMI is that it does not distinguish between fat and muscle, in the general population it is much more likely that an individual with a BMI $>30 \mathrm{~kg} / \mathrm{m}^{2}$ is obese rather than muscular.

The definitive diagnosis of OSA and OSH, however, must be made by some form of sleep study. A complete comprehensive sleep study exam is done by a technologist in a formal soundproof infrared video monitored sleep study laboratory. However, such studies can be logistically complex and expensive to perform and may be relatively inaccessible some areas. Under these circumstances some simpler derivation (eg, portable abbreviated monitoring/screening system) is often performed and may be cost-effective $[15,52]$.

A full sleep study consists of monitoring the EEG (for stage of sleep and arousal), the EOG (for NREM versus REM sleep), oral and nasal airflow sensors and capnography (for actual movement of air), noise (for snoring and snorting),

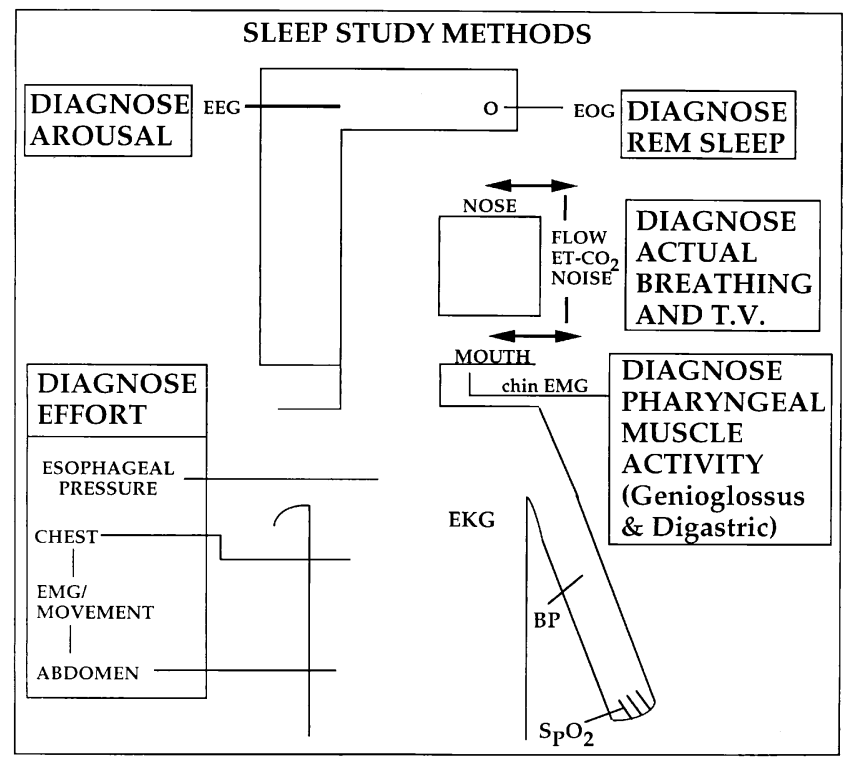

Fig. 5. Schematic illustrating the methodology of polysomography (sleep study). (From Benumof JL. Obstructive sleep apnea in the adult obese patient: implications for airway management. J Clin Anesth 2001;13(2):144-56, with permission.) 
esophageal pressure and chest and abdominal movements (for breathing effort), submental and extremity EMG (for pharyngeal [genioglossus] muscle activity and extremity movement, respectively), oximetry (pulse, ear, transcutaneous) (for $\mathrm{SpO}_{2}$ and noninvasive blood pressure), and ECG (for cardiovascular function) (Fig. 5). Rarely, direct systemic and pulmonary artery pressure monitoring is performed for more precise determination of cardiopulmonary function.

Apnea is defined as the cessation of airflow for $>10$ seconds and is considered obstructive if there is respiratory effort during the apnea. Hypopnea is defined as greater than a 50\% reduction in airflow for $>10$ seconds. Fig. 6 shows simple examples of OSA (effort with no flow), central sleep apnea (no effort, no flow), and mixed obstructive and central sleep apnea [66]. Fig. 7 illustrates an example of obstructed breathing during sleep leading to apnea (panel A) and obstructed breathing during sleep leading to hypopnea (panel B) [15].

The results of a sleep study are reported as follows: The total number of apneas and hypopneas per hour is called the apnea-hypopnea index (AHI) and is used to define the severity of OSA; values of $5-15,16-30$, and $>30$ indicate mild, moderate, and severe OSA, respectively. The total number of arousals per hour is reported as a total arousal index (TAI, arousal/hour). The sum of AHI and TAI is called the respiratory disturbance index (RDI). Central sleep apneas (no flow, no effort) are usually reported separately. In morbidly obese patients who required treatment for OSA (mean [range] BMI $=48.7[32.4-78.6]$ and age $=41$ [28-63]), the percent of central apneas out of the total AHI equaled only 5.8\% [42].

Oxygen data are reported in several ways. Most laboratories report the number of $\mathrm{SaO}_{2}$ desaturations greater than $4 \%$, the lowest $\mathrm{SaO}_{2}$, and time spent at a certain

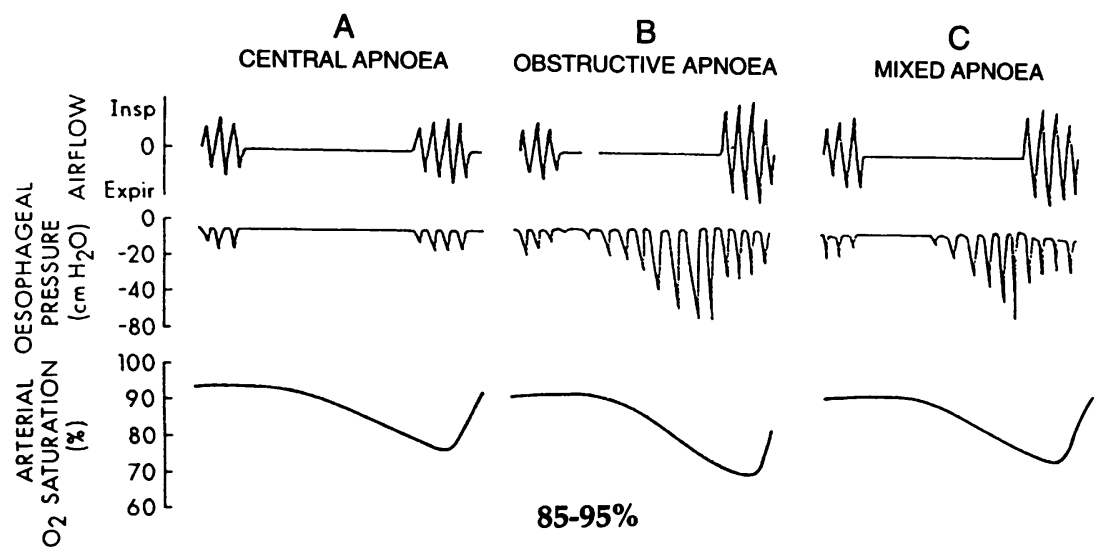

Fig. 6. Simple classical examples of central sleep apnea. Panel A = no effort, no flow; Panel B = obstructive apnea (effort, no flow); and Panel $\mathrm{C}=$ mixed apnea (initially no effort, then effort, but no flow). Effort is indicated by downward, negative deflections in esophageal pressure. As illustrated, all three types of apnea result in large decreases in arterial oxygen saturation. In the typical patient with obstructive sleep apnea, $85 \%$ to $95 \%$ of the apneas are purely obstructive, some are mixed, and a few are central. (Adapted from Boushra NN. Anaesthetic management of patients with sleep apnea syndrome. Can J Anaesth 1996;43:599-616, with permission.) 

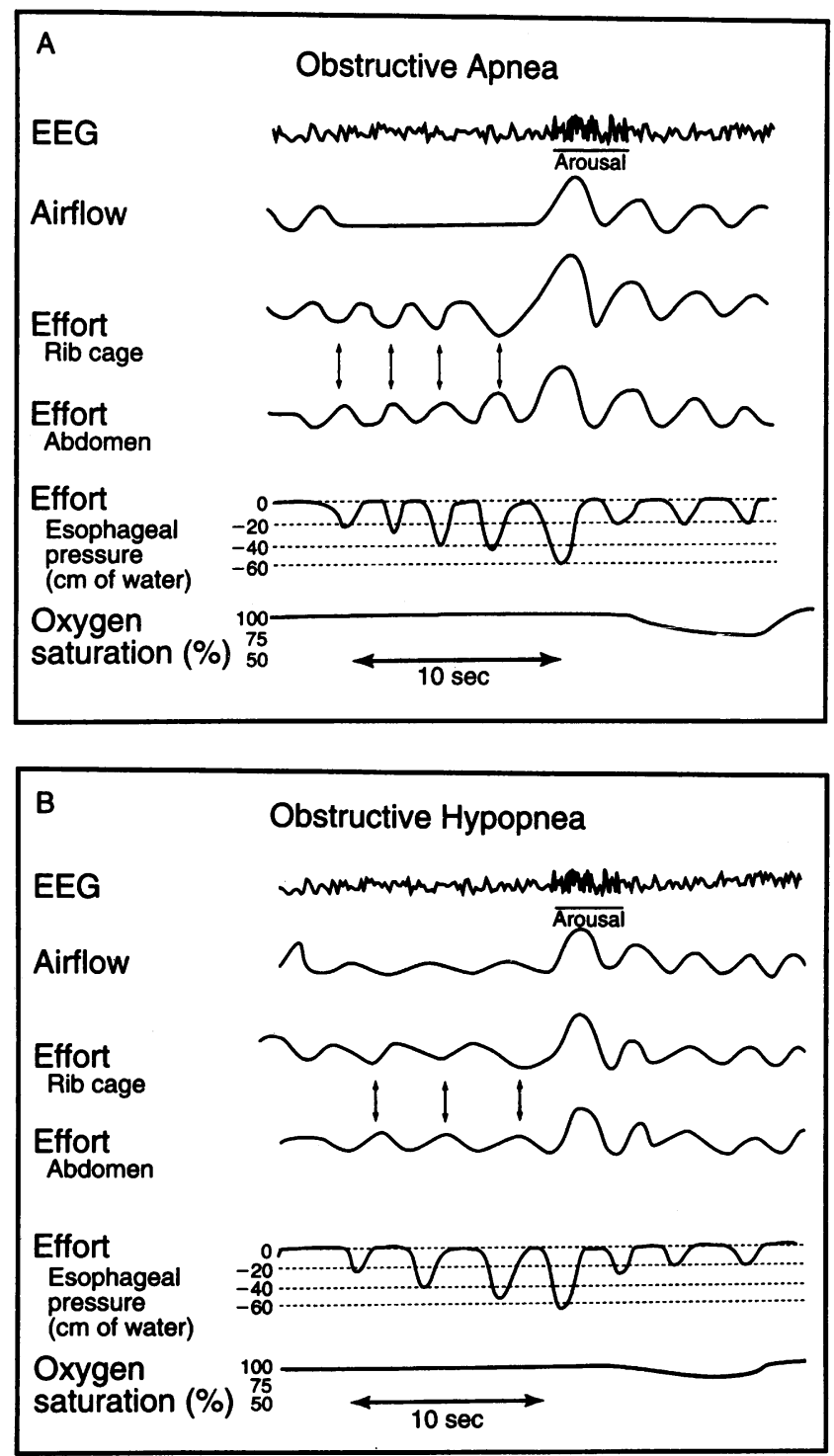

Fig. 7. Simple examples of obstructed breathing during sleep leading to apnea (A) and hypopnea (B). Increasing effort to inspire (esophageal pressure) against the obstructed upper airway results in paradoxical chest and abdominal movement, which are indicated by the small vertical arrows. (From Strollo PJ, Rogers RM. Obstructive sleep apnea. Current concepts. N Engl J Med 1996;334:99-104, with permission.) 
range of $\mathrm{SaO}_{2}$ (eg, $89 \%-80 \%, 79 \%-70 \%$, etc.). The cardiovascular manifestations of $\mathrm{SaO} 2$ desaturation are variously described but always include maximum and minimum heart rate and blood pressure during the event and the occurrence of any arrthymias or ECG changes that are consistent with myocardial ischemia. If $\mathrm{N}-\mathrm{CPAP}$ was used for part of the sleep period, then all of the above data will be reported with and without N-CPAP.

\section{Effect of anesthetic drugs on airway patency in the adult obese OSA patient}

All central depressant drugs diminish the action of the pharyngeal dilator muscles in adult obese OSA patients, thereby promoting pharyngeal collapse around a fat laden pharynx [67-73]. The commonly-used anesthetic drugs that have been demonstrated to cause pharyngeal collapse are propofol [74], thiopental $[75,76]$, narcotics [70,77,78], benzodiazepines [70,79-81], small doses of neuromuscular blockers [82-84], and nitrous oxide [85]. The anesthetic druginduced pharyngeal collapse around the excessive airway tissue "makes the airway lumen resemble the interior of the intestine and the path of the airway easily becomes lost among the folds" [86]. Furthermore, if opioids cause airway obstruction, then the opioids may also cause a poor ventilatory response to the ensuing hypoxemia and hypercapnia [87].

It is important to understand that in the postoperative setting, sleep architecture is disturbed. During the first three days after surgery, pain scores are highest and deep stage 3 and 4 NREM and REM sleep are often suppressed [88]. High levels of pain result in increased analgesic requirements during the first three postoperative days, and from this perspective, the danger of life-threatening apnea during drug-induced sleep is increased. In the next three days, deep REM sleep rebounds $[88,89]$. During this phase of recovery the danger of life-threatening natural deep sleep-induced apnea is increased. Thus, for separate in-series reasons (increased analgesic requirement followed by increased amount of REM sleep), the risk of prolonged apnea during sleep is increased for approximately one week for the postoperative OSA patient [90,91].

Given that airway obstruction is more likely when either drug- or REM sleepinduced pharyngeal collapse occurs, it is not surprising that heavy snorers (identified preoperatively) have more severe decreases in $\mathrm{SpO}_{2}$ during sleep postoperatively than normal patients [92]. This consideration is highlighted by numerous reports of the need for rescue airway management in postoperative OSA patients [93-100].

\section{Implications for airway management}

\section{Preoperative evaluation: OSA and airway status}

Since most adult obese patients with OSA are undiagnosed, many who presently require anesthesia and surgery have neither a presumptive clinical nor sleep study 
diagnosis of OSA. The essential items on history that must be present for a presumptive clinical diagnosis of OSA in the adult obese patient are history of snoring and/or snorting and/or apnea during sleep and daytime sleepiness. The severity of these historical items correlates with the severity of sleep study-proven OSA $[6,7,15,26,101]$. Since a firm diagnosis of OSA will likely impact on anesthetic management, it is reasonable to suggest that all adult obese patients (or those who observe them while asleep) be routinely asked about nocturnal snoring/snorting/ apnea and diurnal sleepiness [91,92,102]. Prediction of OSA is increased if there is a history of hypertension [64] or a neck circumference $>40-42 \mathrm{~cm}[39,40,64]$. Other signs and symptoms consistent with a clinical presumptive diagnosis of OSA are nocturnal diaphoresis and enuresis, frequent nocturia, morning headaches, abnormal cardiovascular, and neuropsychiatric function (see fig. 4).

If the anesthesiologist is the first care-giver to diagnose OSA, then it may sometimes be prudent to postpone the surgery and refer the patient to an appropriate physician and perhaps a formal sleep study obtained to quantify the severity of OSA. Alternatively, if general anesthesia is required, the patient could be treated as though severe OSA existed (see remainder of article). Finally, regional anesthesia is worth considering if it can be technically performed, the awake patient can tolerate the surgical position, and the respiratory effects of the regional anesthetic, access to the airway is adequate, and the surgery can be quickly terminated. Regional anesthesia may obviate the need for sedative and narcotic drugs both intra- and postoperatively.

\section{Tracheal intubation}

Several lines of evidence in the literature indicate that obese OSA patients are, in general, more difficult to intubate than normal controls. First, obesity is significantly related to difficult intubation [103-105]. Indeed, in two series of morbidly obese patients undergoing upper abdominal surgery, the incidence of difficult of intubation under general anesthesia was $13 \%$ and $24 \%$ and the incidence of patients requiring awake intubation was $8 \%$ in both studies $[68,106]$. Second, a short thick neck is significantly related to difficult intubation $[103,107]$. Third, obesity $[1,2$, 5-7] and a short thick neck [36-41,64] are significantly related to OSA and to each other [103]. Fourth, since excess pharyngeal tissue is deposited in the lateral walls of the pharynx of obese OSA patients [13,29-33], the excess tissue may not be visualized during routine oropharyngeal classification. Finally, based on the above, it is not surprising that difficult intubation and OSA had been found to be significantly related [108]. In fact, the strength of the relationship was such that the author felt that "all patients who have a trachea that is difficult to intubate should be regarded as having OSA until excluded by clinical features and, where doubt exist, sleep studies." Indeed, in one large series of patients undergoing surgery for OSA, the incidence of failed intubation was 5\% [93]. Thus, given the above literature, and the fact that excess pharyngeal tissue may not be revealed by routine examination, it is reasonable that the practitioner have an increased index of suspicion regarding intubation difficulty. 
Several more tracheal intubation points are especially relevant to obese OSA patients. Within the context of an increased index of suspicion of intubation difficulty, the decision as to whether to do tracheal intubation with the patient awake or under general anesthesia must be individualized on the basis of a complete preoperative airway evaluation. If difficulty with either mask ventilation or tracheal intubation is expected, then according to the ASA Difficult Airway Algorithm, intubation and extubation should be performed while the patient is awake [109-111].

If tracheal intubation is to be done while the patient is awake, it is essential that the patient be properly prepared. One component of proper preparation is judicious administration of sedative and analgesic medication [68,71]. The danger of premedication in these patients is well illustrated by descriptions of several cases of complete airway obstruction [112-115]. Thus, proper preparation should depend on thorough topical and nerve block anesthesia of the upper airway [106,110]. Use of a flexible fiberscope through a rigid oropharyngeal conduit technique of intubation permits visualization of structures in an atraumatic manner [111,116].

If intubation is to be done with the patient asleep, it is important to fully preoxygenate the patient because the obese patient with a relatively small FRC

\section{TIME TO HEMOGLOBIN DESATURATION WITH INITIAL $\mathbf{F A O}_{\mathbf{2}}=\mathbf{0 . 8 7}$}

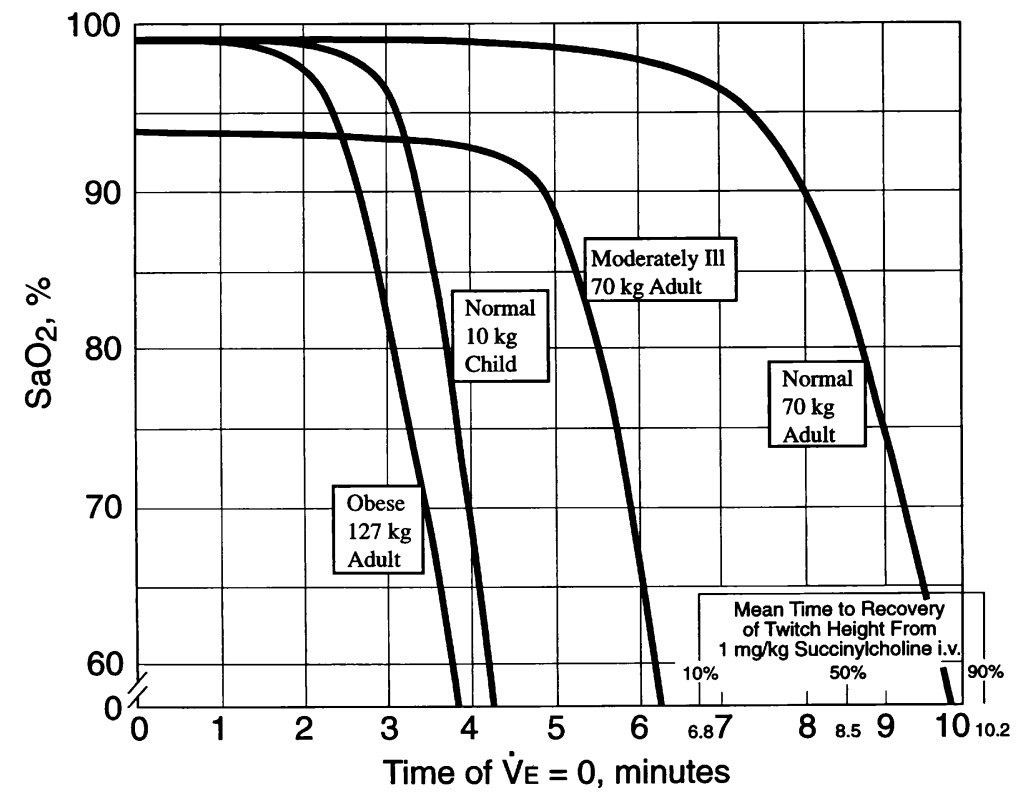

Fig. 8. $\mathrm{SaO}_{2}$ versus time of apnea for various types of patients. The $\mathrm{SaO}_{2}$ curves were produced by the computer apnea model of Reference [118]. An $\mathrm{FaO}_{2}=0.87$ corresponds to an $\mathrm{FIO}_{2}=1.0$. (From Benumof JL, Dagg R, Benumof R. Critical hemoglobin desaturation will occur before return to an unparalyzed state following $1 \mathrm{mg} / \mathrm{kg}$ intravenous succinylcholine. Anesthesiology 1997;87:979-82, with permission.) 
(small oxygen reservoir) and high oxygen consumption desaturates much more rapidly during obstructive apnea compared with a normal patient $[117,118]$ (Fig. 8).Maximal total body preoxygenation (filling of the alveolar, arterial, venous, and tissue spaces) requires that the patient breathe $\mathrm{F}_{\mathrm{I}} \mathrm{O}_{2}=1.0$ for $\geq 3$ minutes in a well sealed system [119]. Fig. 9 shows how decreasing initial $\mathrm{FaO}_{2}$ (eg, resulting from a poorly sealed preoxygenation system) results in progressively more rapid oxyghemoglobin desaturation during obstructive apnea in a BMI $=40 \mathrm{~kg} / \mathrm{m}^{2}$ patient $[117,118]$. Oxygen insufflation into the pharynx via a small nasopharyngeal catheter during laryngoscopy of the obese patient may further delay the onset on arterial oxygen desaturation [119,120]. Laryngoscopy must be performed in an optimal manner, which means that the patient is in the optimal "sniff" position before induction of general anesthesia (may require building a ramp under the patient from the scapula to the head) and optimal external laryngeal manipulation should be used on the first attempt if the view of the larynx is poor $[121,122]$. Mask ventilation must be performed optimally, which may require two anesthesia providers using two- or three-handed bilateral jaw thrust and mask seal, with oropharyngeal and/or nasopharyngeal airways in situ, and the airway pressure relief valve and mask seal set so that CPAP $\left(5-15 \mathrm{~cm} \mathrm{H}_{2} \mathrm{O}\right)$ is delivered to the pharynx. "Cannot ventilate, cannot intubate" options must be immediately available at the anesthetizing location [109-111].

\section{Body Mass Index $=40 \mathrm{~kg} / \mathrm{m}^{2}$}

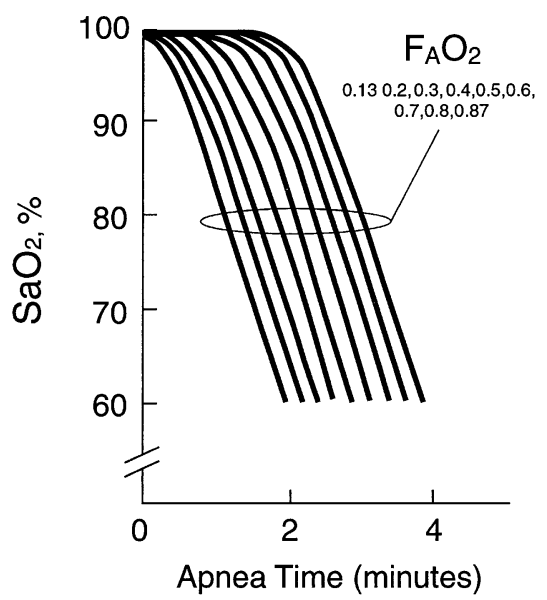

Fig. 9. $\mathrm{SaO}_{2}$ versus time of apnea for a patient with a $\mathrm{BMI}=40 \mathrm{~kg} / \mathrm{m}^{2}$ for various initial preapnea $\mathrm{FaO}_{2}$. The family of curves was produced by the apnea model of Reference [118]. $\mathrm{An}^{\mathrm{FaO}_{2}}=0.87$ (most right-hand curve) corresponds to an $\mathrm{F}_{\mathrm{I}} \mathrm{O}_{2}=1.0$ and an $\mathrm{Fa}_{2}=0.13$ (most left-hand curve) corresponds to an $\mathrm{F}_{1} \mathrm{O}_{2}=0.21$. The $\mathrm{FaO}_{2}=0.87$ desaturation curve (most right-hand curve) is the same as the desaturation curve for the 127-kg patient in Fig. 8. (From Benumof JL. Obstructive sleep apnea in the adult obese patient: implications for airway management. J Clin Anesth 2001;13(2): $144-56$, with permission.) 


\section{Extubation: awake versus leaving the tube in}

The risk of airway obstruction following extubation is increased in OSA patients [123]. The risk is further increased in OSA patients who have had nasal packing following nasal surgery [124]; therefore, packing around a nasopharyngeal airway (creating a central conduit for gas exchange) should be considered $[69,91]$. In a retrospective review of 135 patients undergoing surgery for the treatment of OSA, the incidence of life-threatening postextubation obstruction was $5 \%$; those patients who obstructed were extubated in the operating room [93]. Aside from the threat of death from airway obstruction, another great danger of spontaneous ventilation against an obstructed airway is rapid development of severe negative pressure pulmonary edema [93,125]. The treatment of negative pressure pulmonary edema in this setting usually requires re-intubation [125].

Depending on the mask ventilation and tracheal intubation experience at the beginning of the case, the length and type of surgery, and the severity of the OSA, one should consider leaving the patient intubated for a period of postoperative mechanical ventilation. Whenever the patient is to be extubated (either in the operating room or later in the PACU or ICU) the patient should be fully awake. A dangerous mistake is to interpret mindless movement, such as reflex reaching for an endotracheal tube or suddenly trying to sit up, for purposeful movement. Full recovery from neuromuscular blockade should be proven by a neuromuscular blockade monitor, sustained head lift for $>5$ seconds and, in the ICU, with an adequate vital capacity and peak inspiratory pressure. The patient should not have a high blood level of narcotic as indicated by a respiratory rate $<12-14$ breaths/ minute while the endotracheal tube is in situ. It is helpful for regional analgesia to be operative at the time of extubation. Extubation in the reverse Trendelenburg or semi-upright position minimizes compression of the diaphragm by abdominal contents [126].

When extubating, an oropharyngeal and/or a long nasopharyngeal airway (ie, it is desirable for the distal end to be retroglossal) should be in situ if possible and two-person mask ventilation should be ready to be applied. If doubt exists about the ability of the patient to breathe adequately and the practitioner to re-intubate if the patient does breathe inadequately, then the tracheal tube should be removed over an airway exchange catheter or fiberscope [127]. If the patient does well initially, one should consider pneumatically splinting the oropharynx by applying N-CPAP, first with oxygen and then later with air $[123,128]$. Beyond the initial immediate application of N-CPAP, the $\mathrm{F}_{\mathrm{I}} \mathrm{O}_{2}$ should only be increased if the $\mathrm{SpO}_{2}$ is significantly decreased [94].

\section{Opioid pain management: location of patient}

Obese OSA patients have an increased risk of opioid-induced upper airway obstruction (even epidural and patient controlled analgesia may be problematic) $[96,97]$ and is a reason why these patients may need a monitored care environment (ie, continuous electronic and frequent visual monitoring [respiratory rate, 
sedation level, snoring]) [95]. Factors to be considered in this risk benefit analysis are the BMI of the patient, the AHI (ie, the severity of the OSA), the degree of associated cardiopulmonary disease, and the postoperative narcotic requirement. When all of these factors are mild, then the patient may reasonably go to a relatively unmonitored environment, and when any of these factors are severe, the patient should go to an ICU. The large gray zone in between these extremes requires careful judgment. Putting aside the one negative report involving epidural opioids in a OSA patient [96], the risk of opioid-induced airway obstruction may be avoidable by using alternative techniques, for example, regional block with local anesthesia to provide postoperative analgesia [129].

\section{Summary}

Adult obese patients with suspected or sleep test confirmed OSA present a formidable challenge throughout the perioperative period. Life-threatening problems can arise with respect to tracheal intubation, tracheal extubation, and providing satisfactory postoperative analgesia. Tracheal intubation and extubation decisions in obese patients with either a presumptive and/or sleep study diagnosis of OSA must be made within the context that there may be excess pharyngeal tissue that cannot be visualized by routine examination, and the literature indicates an increased risk of intubation difficulty. Regional anesthesia for postoperative pain control is desirable (although such management is not necessary or possible for many of these patients). If opioids are used for the extubated postoperative patient, then one must keep in mind an increased risk of pharyngeal collapse and consider the need for continuous visual and electronic monitoring. The exact management of each sleep apnea patient with regard to intubation, extubation, and pain control requires judgment and is a function of many anesthesia, medical, and surgical considerations.

\section{References}

[1] Young T, Palta M, Dempsey J, Skatrud J, Weber S, Badr S. The occurrence of sleep-disordered breathing among middle-aged adults. N Engl J Med 1993;328:1230-5.

[2] Bresnitz E. Epidemiology of obstructive sleep apnea. Epidemiol Rev 1994;16:210-27.

[3] Anocli-Israel S, Kripke DF, Klauber MR, Mason WJ, Fell R, Kaplan O. Sleep-disordered breathing in community-dwelling elderly. Sleep 1991;14:485-95.

[4] Barthel SW, Strome M. Snoring, obstructive sleep apnea and surgery. Med Clin North Am 1999;83:85-96.

[5] Strohl KP, Redline S. Recognition of obstructive sleep apnea. Am J Respir Crit Care Med 1996;154:279-86.

[6] Guilleminault C, Tikian A, Dement W. The sleep apnea syndromes. Annu Rev Med 1976; 27:465-84.

[7] Willett WC, Dietz WH, Colditz GA. Guidelines for healthy weight. N Engl J Med 1999;341: 427-34.

[8] National Commission on Sleep Disorders Research. Wake up America: a national sleep alert. Washington, DC: Government Printing Office; 1993. 
[9] Young T, Evans L, Finn L, Palta M. Estimation of the clinically diagnosed proportion of sleep apnea syndrome in middle-aged men and women. Sleep 1997;20:705-6.

[10] Callop NA. Conundrums in sleep medicine. Chest 1999;115:607-8.

[11] Pack AI, Gurubhagavatula I. Economic implications of the diagnosis of obstructive sleep apnea. Ann Intern Med 1999;130:533-4.

[12] Sakakibara H, Tong M, Matsushita K, Hirata M, Konishi Y, Suetsugh S. Cephalometric abnormalities in non-obese and obese patients with obstructive sleep apnea. Eur Respir J 1999; 13:403-10.

[13] Mortimore IL, Marshal I, Wraith PK, Sellar RJ, Douglas NJ. Neck and total body fat deposition in nonobese and obese patients with sleep apnea compared with that in control subjects. Am J Respir Crit Care Med 1998;157:280-3.

[14] Davidson-Ward SL, Marcu CL. Obstructive sleep apnea in infants and young children. J Clin Neurophysiol 1996;13:198-207.

[15] Strollo PJ, Rogers RM. Obstructive sleep apnea. current concepts. N Engl J Med 1996;334: 99-104.

[16] Barsh CI. The origin of pharyngeal obstruction during sleep. Sleep and breathing 1999;3: $17-21$.

[17] Deegan PC, McNicholas WT. Pathophysiology of obstructive sleep apnea. Eur Respir J 1995;8:1161-78.

[18] White DP. Pathophysiology of obstructive sleep apnea. Thorax 1995;50:797-804.

[19] Horner RL, Innes JA, Holden HB, Guy A. Afferent pathways for pharyngeal dilator reflex to negative pressure in man: a study using upper airway anesthesia. J Physiol 1991;436: $31-44$.

[20] Pierce RJ, Worsnop CJ. Upper airway function and dysfunction in respiration. Clin Exp Pharm Physiol 1999;26:1-10.

[21] Hudgel DW. Palate and hypopharynx: sites of inspiratory narrowing of the upper airway during sleep. Am Rev Respir Dis 1988;138:1542-7.

[22] Wiegand I, Zwillich CW, White DP. Collapsibility of the human airway during normal sleep. J Appl Physiol 1989;66:1800-8.

[23] Morrell MJ, Arabi Y, Zahn B, Badr MS. Progressive retropalatal narrowing preceding obstructive apnea. Am J Respir Crit Care Med 1998;158:1974-81.

[24] Schwab RI, Pack AI, Gupta KB, Metzger JL, Oh E, Getsy JE, et al. Upper airway and soft tissue structural changes induced by CPAP in normal subjects. Am J Respir Crit Care Med 1996;154:1106-16.

[25] Bloom JW, Kaltenborn WT, Quan SF. Risk factors in a general population for snoring: Importance of cigarette smoking an obesity. Chest 1988;93:678-83.

[26] Wilson K, Stoohs RA, Mulrooney TF, Johnson LJ, Guilleminault C, Huang Z. The snoring spectrum: acoustic assessment of snoring sound intensity in 1,139 individuals undergoing polysomography. Chest 1999;115:765-70.

[27] White DP, Lombard RM, Cadieux RJ, Zwillich CW. Pharyngeal resistance in normal humans: influence of gender, age and obesity. J Appl Physiol 1985;58:365-71.

[28] Brown IG, Zamel N, Hoffstein V. Pharyngeal cross-sectional area in normal men and women. J Appl Physiol 1986;61:890-5.

[29] Horner RL, Mohiaddin RH, Lowell DG, Shea SA, Burman ED, Longmore DB, et al. Sites and sizes of the fat deposits around the pharynx in obese patients with obstructive sleep apnea and weight matched controls. Eur Respir J 1989;2:613-22.

[30] Mayer P, Pepin JL, Bettega G, Veale D, Ferrette G, Deschaux C, et al. Relationship between body mass index, age and upper airway measurements in snorers and sleep apnea patients. Eur Respir J 1996;9:1801-9.

[31] Shelton KE, Gay SB, Hollowell DE, Woodson H, Suratt PM. Mandible enclosure of upper airway and weight in obstructive sleep apnea. Am Rev Respir Dis 1993;148:195-200.

[32] Shelton KE, Gay SB, Woodson H, Gay S, Suratt PM. Pharyngeal fat in obstructive sleep apnea. Am Rev Respir Dis 1993;148:462-6. 
[33] Schwab RJ, Gupta KB, Gefter WB, Metzger LJ, Hoffman EA, Pack AI. Upper airway soft tissue anatomy in normal subjects and patients with sleep-disordered breathing. Significance of the lateral pharyngeal walls. Am J Respir Crit Care Med 1995;152:1673-89.

[34] Rubinstein I, Colapinto N, Rotstein LE, Brown IG, Hoffstein V. Improvement in upper airway function after weight loss in patients with obstructive sleep apnea. Am Rev Resp Dis 1988; 138:1192-5.

[35] Leiter JC. Upper airway shape. Is it important in the pathogenesis of obstructive sleep apnea? Am J Respir Crit Care Med 1996;153:894-8.

[36] Koenig JE, Thach BT. Effects of mass loading on the upper airway. J Appl Physiol 1988;64: 2294-9.

[37] Koopmann CF, Field RA, Coulthard SW. Sleep apnea syndrome associated with a neck mass. Otolaryngol Head Neck Surg 1981;89:949-52.

[38] Hoffstein V, Mateika S. Differences in abdominal and neck circumferences in patients with and without obstructive sleep apnea. Eur Respir J 1992;5:377-81.

[39] Davies RJO, Stradling JR. The relationship between neck circumference, radiographic pharyngeal anatomy, and the obstructive sleep apnoea syndrome. Eur Respir J 1990;3: $509-14$.

[40] Stradling JR, Crosby JH. Predictors and prevalence of obstructive sleep apnoea and snoring in 1,001 middle aged men. Thorax 1991;46:85-90.

[41] Davies RJO, Ali NJ, Stradling JR. Neck circumference and other clinical features in the diagnosis of the obstructive sleep apnea syndrome. Thorax 1992;47:101-5.

[42] Vgontzas AN, Tan TL, Bixler EO, Martin LF, Shubert D, Kales A. Sleep apnea and sleep disruption in obese patients. Arch Intern Med 1994;154:1705-11.

[43] Rajala R, Partinen M, Sane T, Pelkonen R, Huikur K, Seppalainen AM. Obstructive sleep apnoea syndrome in morbidly obese patients. J Intern Med 1991;230:125-9.

[44] Bowes G, Townsend ER, Bromley SM, Kozar LF, Phillipson EA. Role of carotid body and of afferent vagal stimuli in the arousal response to airway occlusion in sleeping dogs. Am Rev Respir Dis 1981;123:644-7.

[45] Bowes G, Townsend ER, Kozar LF, Bromley SM, Phillipson EA. Effect of carotid body denervation on arousal response in sleeping dogs. J Appl Physiol 1981;51:40-5.

[46] Berthon-Jones M, Sullivan CE. Ventilation and arousal responses to hypercapnea in normal sleeping humans. J Appl Physiol 1984;54:59-67.

[47] Kimoff RJ, Cheong TH, Olha AE, Charbonneau M, Levy RD, Cosio MG, et al. Mechanisms of apnea termination in obstructive sleep apnea: role of chemoreceptor and mechanoreceptor stimuli. Am J Respir Crit Care Med 1994;149:707-14.

[48] Gleeson K, Zwillich CW, White DP. The influence of increasing ventilatory effort on arousal from sleep. Am Rev Respir Dis 1990;142:295-300.

[49] Issa FG, McNamara SG, Sullivan CE. Arousal responses to airway occlusion in sleeping dogs: comparison of nasal and tracheal occlusions. J Appl Physiol 1987;62:1832-6.

[50] Guilleminault C, Connolly SJ, Winkle RA. Cardiac arrhythmia and conduction disturbances during sleep in 400 patients with sleep apnea syndrome. Am J Cardiol 1983;52:490-4.

[51] Orr WC. Sleep apnea, hypoxemia and cardiac arrhythmias [editorial]. Chest 1986;89:1-2.

[52] Man GCW. Obstructive sleep apnea: ciagnosis and treatment. Med Clin North Am 1996;80: $803-20$.

[53] Schafer H, Hasper SE, Koehler U, Latzelsberger J, Tasci S, Luderitz B. Pulmonary hemodynamics in obstructive sleep apnea: time course and associated factors. Eur Respir J 1998;12: $679-84$.

[54] Shepard JW. Gas exchange and hemodynamics during sleep. Med Clin North Am 1985; 69:1243-64.

[55] Fletcher EC. The relationship between systemic hypertension and obstructive sleep apnea: facts and theory. Am J Med 1995;98:118-28.

[56] Millman RP, Redline S, Carlisle CC, Assaf AR, Levinson PD. Daytime hypertension in obstructive sleep apnea. Prevalence and contributing risk factors. Chest 1991;99:861-6. 
[57] Berman EJ, DiBenedetto RJ, Causey DE, Mims T, Conneff M, Goodman LS, et al. Right ventricular hypertrophy detected by echocardiography in patients with newly diagnosed obstructive sleep apnea. Chest 1991;100:347-50.

[58] He J, Kryger MH, Zorick FJ, Conway W, Roth T. Mortality and apnea index in obstructive sleep apnea: experience in 385 male patients. Chest 1988;94:9-14.

[59] Palomaki H, Partinen M, Erkinjuntti J, Kaste M. Snoring, sleep apnea syndrome, and stroke. Neurology 1992;42(Suppl 6):75-82.

[60] Partinen M, Guilleminault C. Daytime sleepiness and vascular morbidity at seven-year followup in obstructive sleep apnea patients. Chest 1990;97:27-32.

[61] Teran-Santos J, Jimenez-Gomez A, Cordero-Guevara J, Cooperative Group Burgos-Santander. The association between sleep apnea and the risk of traffic accidents. N Engl J Med 1999;340: $847-51$.

[62] Findley LJ, Unverzagt ME, Suratt PM. Automobile accidents involving patients with obstructive apnea sleep. Am Rev Respir Dis 1988;138:337-40.

[63] Suratt PM, Findley LJ. Driving with sleep apnea. N Engl J Med 1999;340:881-3.

[64] Flemons WW, Whitelaw WA, Brant R, Remmers JE. Likelihood ratios for a sleep apnea clinical prediction rule. Am J Respir Crit Care Med 1994;150:1279-85.

[65] Obesity: preventing and managing the global epidemic: report of a WHO consultation on obesity, Geneva, June 3-5, 1997. Geneva: World Health Organization; 1998.

[66] Orr WC. Utilization of polysomnography in the assessment of sleep disorders. Med Clin North Am1985;69:1153-67.

[67] Boushra NN. Anaesthetic management of patients with sleep apnoea syndrome. Can J Anaesth 1996;43:599-616.

[68] Buckley FP, Robinson NB, Simonowitz DA, Dillinger EP. Anaesthesia in the morbidly obese: a comparison of anaesthetic and analgesic regimens for upper abdominal surgery. Anaesthesia $1983 ; 38: 840-51$.

[69] Hanning CD. Obstructive sleep apnea. Br J Anaesth 1989;63:477-88.

[70] Chung F, Crago RR. Sleep apnea syndrome and anaesthesia. Can Anaesth Soc J 1982; 29:439-43.

[71] Connolly CA. Anesthetic management of obstructive sleep apnea patients. J Clin Anesth 1991;3:461-9.

[72] Hwang JC, St John WM, Bartlett D. Respiratory related hypoglossal nerve activity: influence of anesthetics. J Appl Physiol 1983;55:785-92.

[73] Nishino T, Shirahata M, Yonezawa T, Honda Y. Comparison of changes in the hypoglossal and phrenic nerve activity in response to increasing depth of anesthesia in cats. Anesthesiology 1984;60:19-24.

[74] Mathru M, Esch O, Lang J, Herbert ME, Chaljub G, Goodacre B, et al. Magnetic resonance imaging of the upper airway: Effect of propofol anesthesia and nasal continuous positive airway pressure in humans. Anesthesiology 1996;84:273-9.

[75] Drummond GB. Influence of thiopentone on upper airway muscles. Br J Anaesth 1989;63: $12-21$.

[76] Nandi PR, Charlesworth CH, Taylor SJ, Nunn JF, Dore CJ. Effect of general anaesthesia on the pharynx. Br J Anaesth 1991;66:157-62.

[77] Catley DM, Thornton C, Jordan C, Lehane JR, Royston D, Jones JG. Pronounced, episodic oxygen desaturation in postoperative period: its association with ventilatory pattern and analgesic regimen. Anesthesiology 1985;63:20-8.

[78] Robinson RW, Zwillich CW, Bixler EO, Cadieux RJ, Kales A, White DP. Effects of oral narcotics on sleep-disordered breathing in healthy adults. Chest 1987;91:197-203.

[79] Leiter JC, Knuth SL, Krol RC, Bartlett Jr D. The effect of diazepam on genioglossal muscle activity in normal human subjects. Am Rev Respir Dis 1985;132:216-9.

[80] Montravers P, Dureuil B, Desmonts JM. Effects of IV midazolam on upper airway resistance. Br J Anaesth 1992;68:27-31.

[81] Zivkovic B, Perrault G, Morel E, Sanger DJ. Comparative pharmacology of zolpidem and other 
hypnotics and sleep inducers. In: Sauvant JP, Langer SZ, Morselli PL, editors. Imidazopyridines in sleep disorders. New York: Raven Press; 1988. p. 97-109.

[82] Bruce DL, Downs JB, Kulkarni PS, Capan LM. Precurarization inhibits maximal ventilatory effort. Anestheisology 1984;61:618-21.

[83] Musich J, Walts LF. Pulmonary aspiration after a priming dose of vecuronium. Anesthesiology 1986;64:517-9.

[84] Pavlin EG, Holle RH, Schoene RB. Recovery of airway protection compared with ventilation in humans after paralysis with curare. Anesthesiology 1989;70:381-5.

[85] Beydon L, Lafaso F, Heyer L, Delaunay L, Goldenberg F. Nitrous oxide induces central and obstructive apneas in normal subjects. Br J Anaesth 1994;72(Suppl 1):A113.

[86] Craddock M, Lees DE. Anesthesia for obstructive sleep apnea: risks, precautions, and management. In: Fairbanks DNF, Fujita S, Ikematsu T, Simmons FB, editors. Snoring and obstructive sleep apnea. New York: Raven Press; 1987. p. 235.

[87] Phillipson EA, Sullivan CE. Arousal: the forgotten response to respiratory stimuli. Am Rev Respir Dis 1978;118:807-9.

[88] Knill RL, Moote CA, Skinner MI, Rose EA. Anesthesia with abdominal surgery leads to intensive REM sleep during the first postoperative week. Anesthesiology 1990;73:52-61.

[89] Reeder MK, Goldman MD, Loh L, Muir AD, Casey KR, Lehane JR. Late postoperative nocturnal dips in oxygen saturation in patients undergoing major abdominal vascular surgery. Predictive value of pre-operative overnight pulse oximetry. Anaesthesia 1992;47:110-5.

[90] Reeder MK, Goldman MD, Loh L, Muir AD, Casey KR, Gitlin DA. Postoperative obstructive sleep apnoea. Haemodynamic effects of treatment with nasal CPAP. Anaesthesia 1991; 46:849-53.

[91] Dodds C. Sleep apnoea and anaesthesia. Recent Advances in Anaesthesia and Analgesia 1994;18:179-85.

[92] Gentil B, Lienhart A, Fleury B. Enhancement of postoperative desaturation in heavy snorers. Anesth Analg 1995;81:389-92.

[93] Esclamado RM, Glenn MG, McCulloch TM, Cummings CW. Perioperative complications and risk factors in the surgical treatment of obstructive sleep apnea syndrome. Laryngoscope 1989; 99:1125-9.

[94] Jones JG, Jordan C, Scudder C, Rocke DA, Barrowcliffe M. Episodic postoperative oxygen desaturation: the value of added oxygen. J R Soc Med 1985;78:1019-22.

[95] Keamy MF, Cadieux RJ, Kofke WA, Kales A. The occurrence of obstructive sleep apnea in a recovery room patient. Anesthesiology 1987;66:232-4.

[96] Larmarche Y, Martin R, Reiher J, Blaise G. The sleep apnoea syndrome and epidural morphine. Can Anaesth Soc J 1986;33:231-3.

[97] VanDercar DH, Martinez AP, De Liser EA. Sleep apnea syndromes: a potential contraindication for patient-controlled analgesia. Anesthesiology 1991;74:623-4.

[98] Tierney NM, Pollard BJ, Doran BRH. Obstructive sleep apnoea. Anaesthesia 1989;44:235-7.

[99] Gabrielczyk MR. Acute airway obstruction after uvulopalatopharyngoplasty for obstructive sleep apnea syndrome. Anesthesiology 1988;69:941-3.

[100] Fairbanks DNF. Uvulopalatopharyngoplasty complications and avoidance strategies. Otolaryngol Head Neck Surg 1990;102:239-45.

[101] Grunstein R, Wilcox I, Yang TS, Hedner J. Snoring and sleep apnoea in men: association with central obesity and hypertension. Int J Obesity 1993;17:533-40.

[102] Vidhani K, Langham BT. Obstructive sleep apnoea syndrome: Is this an overlooked cause of desaturation in the immediate postoperative period. Br J Anaesth 1997;78:442-3.

[103] Rocke DA, Murray WB, Rout CC, Gouws E. Relative risk analysis of factors associated with difficult intubation in obstetric anaesthesia. Anesthesiology 1992;77:67-73.

[104] Rose DK, Cohen MM. The airway: problems and predictions in 18,500 patients. Can J Anaesth 1994;41:372-82.

[105] Wilson ME, Spiegelhalter D, Robertson JA, Lesser P. Predicting difficult intubation. Br J Anaesth 1988;61:211-6. 
[106] Cherit GD, Gonzalez R, Borunda D, Pedroza J, Barranco JG, Herrera MF. Anesthesia for morbidly obese patients. World J Surg 1998;22:969-73.

[107] Cass NM, James NR, Lines V. Difficult direct laryngoscopy complicating intubation for anaesthesia. BMJ 1956;1:488-9.

[108] Hiremath AS, Hillman DR, James AL, Noffsinger WJ, Platt PR, Singer SL. Relationship between difficult intubation and obstructive sleep apnea. Br J Anaesth 1998;80:606-11.

[109] Caplan RA, Benumof JL, Berry FA, Blitt CD, Bode RH, Cheney FW, et al. Practice guidelines for management of the difficult airway. A report by the American Society of Anesthesiologists Task Force on the Management of the Difficult Airway. Anesthesiology 1993;78:597-602.

[110] Benumof JL. Management of the Difficult Airway. With special emphasis on awake tracheal intubation. Anesthesiology 1991;75:1087-110.

[111] Benumof JL. The laryngeal mask airway and the ASA difficult airway algorithm. Anesthesiology 1996;88:686-99.

[112] Hishikawa Y, Furjuya E, Wakamatsu H. Hypersomnia and periodic respiration. Presentation of two cases and comment on the physiopathogenesis of the Pickwickian syndrome. Folia Psychiatry and Neurology of Japan 1970;24:163-73.

[113] Rafferty T, Ruskis A, Sasaki C, Gee J. Perioperative considerations in the management of tracheostomy for the obstructive sleep apnoea patient. Br J Anaesth 1980;52:619-21.

[114] Samuels SI, Rabinov W. Difficulty reversing drug-induced coma in a patient with sleep apnea. Anesth Analg 1986;65:1222-4.

[115] Simmons FB, Hill MW. Hypersomnia caused by upper airway obstructions: a new syndrome in otolaryngology. Ann Otol Rhinol Laryngol 1974;83:670-3.

[116] Rogers S, Benumof JL. New and easy techniques for fiberoptic endoscopy-aided tracheal intubation. Anesthesiology 1983;59:569-72.

[117] Benumof JL, Dagg R, Benumof R. Critical hemoglobin desaturation will occur before return to an unparalyzed state following $1 \mathrm{mg} / \mathrm{kg}$ intravenous succinylcholine. Anesthesiology 1997;87: 979-82.

[118] Farmery AD, Roe PG. A model to describe the rate of oxyhemoglobin desaturation during apnoea. Br J Anaesth 1996;76:284-91.

[119] Benumof JL. Preoxygenation: best method for both efficacy and efficiency [editorial]. Anesthesiology 1999;91:342-4.

[120] Teller LE, Alexander CM, Frumin MJ, Gross JB. Pharyngeal insufflation of oxygen prevents arterial desaturation during apnea. Anesthesiology 1988;69:980-2.

[121] Benumof JL, Cooper SD. Quantitative improvement in laryngoscopic view by optimal external laryngeal manipulation. J Clin Anesth 1996;8:136-40.

[122] Benumof JL. Difficult laryngoscopy: Obtaining the best view [editorial]. Can J Anaesthesia 1994;41:361-5.

[123] Rennotte MT, Baele P, Aubert G, Rodenstein DO. Nasal continuous positive airway pressure in the perioperative management of patients with obstructive sleep apnea submitted to surgery. Chest 1995;107:367-74.

[124] Fairbanks DNF. Risks of nasal packing for epistaxis. Otolaryngol Head Neck Surg 1986;94: $412-5$.

[125] Lang SA, Duncan PG, Shepard DA, Ha HC. Pulmonary oedema associated with airway obstruction. Can J Anaesth 1990;37:210-8.

[126] Burns SM, Egloff MB, Ryan B, Carpenter R, Burns JE. Effect of body position on spontaneous respiratory rate and tidal volume in patients with obesity, abdominal distension and ascites. Am J Crit Care 1994;3:102-6.

[127] Benumof JL. Airway exchange catheter: Simple concept, potentially very dangerous [editorial]. Anesthesiology 1999;91:342-4.

[128] Powell NB, Riley RW, Guilleminault C, Murcia G. Obstructive sleep apnea, continuous positive airway pressure, and surgery. Otolaryngol Head Neck Surg 1988;99:362-9.

[129] Pellacchia DJ, Bretz KA, Barnette RE. Postoperative pain control by means of epidural narcotics in a patient with obstructive sleep apnea. Anesth Analg 1987;66:280-2. 